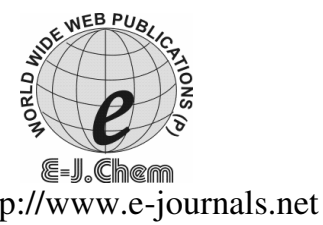

ISSN: 0973-4945; CODEN ECJHAO

E-Journal of Chemistry 2010, 7(1), 265-270

\title{
Column Adsorption and Desorption Studies of Fluoride on Perchloric Acid Cross-Linked Calcium Alginate Beads
}

\author{
Y. VIJAYA and A. KRISHNAIAH ${ }^{*}$ \\ Biopolymers and Thermo Physical Laboratories, \\ Department of Chemistry, \\ Sri Venkateswara University, Tirupati - 517 502, A.P., India. \\ abburikrishnaiah@gmail.com
}

Received 31 July 2009; Accepted 20 September 2009

\begin{abstract}
Contamination of drinking water due to fluoride is a severe health hazard problem. Excess of fluoride $(>1.5 \mathrm{mg} / \mathrm{L})$ in drinking water is harmful to the human health. Various treatment technologies for removing fluoride from ground water have been investigated in the past. Present investigation aims to remove fluoride by perchloric acid cross-linked calcium alginate (PCA). Column flow adsorption data were utilized to obtain breakthrough curves and desorption experiment have been carried out with a view to recover the adsorbed fluoride and regenerate the PCA beads using 0.05 M EDTA. Fourier transform infrared spectroscopy (FTIR) and scanning electron microscopy (SEM) studies were used for the characterization of the adsorbent.
\end{abstract}

Keywords: PCA, Defluoridation, Adsorption, Desorption, Characterization.

\section{Introduction}

It is well documented that trace elements are essential and beneficial to human health in minute concentrations, as they play a significant role in many metabolic processes and act as cofactors. However, exceeding their permissible intake is known to be toxic and adverse effects on general body metabolism. One such trace element, which is ubiquitously distributed in soil, earth and water, is fluoride ${ }^{1}$. Fluoride in drinking water may be beneficial or detrimental depending on its concentration and total amount ingested ${ }^{2}$. Fluoride is beneficial especially to young children (below 8 years of age) when present within permissible limits of $0.5-1.5 \mathrm{mg} / \mathrm{L}$ for the calcinations of dental enamel and bone formation ${ }^{3}$. Concentrations higher than this not only affects teeth and skeleton but also cause several neurological damages in severe cases ${ }^{4}$. 
Various treatment procedures have been reported for the removal of excess fluoride from water. These can be broadly classified into three categories namely, precipitation, adsorption and membrane based. Precipitation involves the addition of soluble chemicals to water. Fluoride is removed either by precipitation, co-precipitation or adsorption onto the formed precipitate. Adsorption involves the passage of contaminated water through an adsorbent bed, where fluoride removed by physical, ion-exchange or surface chemical reaction with adsorbent ${ }^{5}$. Other defluoridation methods include membrane processes, nanofiltration, electrodialysis, etc. These processes are effective and can remove fluoride to a suitable level but they are expensive and require frequent regeneration of beads or membrane and cleaning of the scaling and fouling ${ }^{6}$. Among them adsorption is still widely accepted pollution removal technique because of its ease of operation and cost-effectiveness. Recently, researchers have devoted their study on different types of low-cost but effective materials, clay ${ }^{7}$, brick powder ${ }^{8}$, cotton cellulose $^{9}$, spent bleaching earth ${ }^{10}$, activated carbon ${ }^{11}$, zeolites ${ }^{12}$, redmud $^{13}$, quick lime ${ }^{14}$, etc, .

The scope and objective of this defluoridation study was to investigate the fluoride adsorption capacity of PCA beads by pursuing the column flow adsorption experimental conditions and also to study the desorption (recovery) process. Further the adsorbent was characterized by FTIR (Fourier transform infrared spectroscopy) and SEM (Scanning electron microscopy) to understand the surface morphology.

\section{Experimental}

Sodium alginate was used for preparation of calcium alginate beads were obtained from Loba Chemie, Mumbai, India. Perchloric acid, used for the cross-linking of calcium alginate beads, was obtained from Ranboxy Fine chemicals New Delhi, India. Analytical reagent grade sodium fluoride, ethylene diamine tetra acetic acid from S.D. Fine Chemicals, India was used as source of fluoride and for the regeneration of fluoride. Total ionic strength adjustment buffer (TISAB) was used to eliminate the interference effect of complexing ions from fluoride solution was obtained from Thermo Electron Corporation, USA. Doubly distilled water was used in all experimental work.

\section{Preparation of adsorbent}

Sodium alginate solution was prepared by dissolving and gently heating $40 \mathrm{~g}$ of alginate in $960 \mathrm{~mL}$ of water. The solution was then poured into $2 \%$ calcium chloride solution through the tip of the transfer pipette. The drops of sodium alginate solution gelled into $3.5 \pm 0.1 \mathrm{~mm}$ diameter beads upon contact with calcium chloride solution. The beads were kept in contact with calcium chloride solution for $4 \mathrm{~h}$, which lead to the formation of insoluble and stable beads. Water soluble sodium alginate was converted to water insoluble calcium alginate (CA) beads using $\mathrm{CaCl}_{2}$ solution. The beads were rinsed with double distilled water and dried until the water was completely evaporated. It was observed that the size of the beads decreases on drying. Completely dried bead samples were taken randomly and the size of the each bead was measured by using the micrometer screw gauge with an accuracy of \pm $0.01 \mathrm{~mm}$. The average size of the bead was found to be $2.05 \mathrm{~mm}$. Twenty five grams of prepared calcium alginate beads were soaked in $500 \mathrm{ml}$ of $0.05 \mathrm{M}$ perchloric acid for $4 \mathrm{~h}$. Perchloric acid was cross-linked by calcium alginate beads due to chemical reaction. Then the separated dried beads were used for the experiment.

\section{Column adsorption and desorption studies}

Column studies were carried out in a column made of Pyrex glass of $1.5 \mathrm{~cm}$ internal diameter and $15 \mathrm{~cm}$ length. The column was filled with $1 \mathrm{~g}$ of dried PCA by tapping so that 
maximum amount of adsorbent was packed without gaps. The influent aqueous fluoride solution containing known concentration $(10 \mathrm{mg} / \mathrm{L})$ was filled in the reservoir of large cross sectional area so that the change in the height of the liquid level was negligible during the experiment. Due to the negligible change in the height of the liquid level the flow rate remains constant. The influent solution was allowed to pass through the bed at constant flow rate of $2 \mathrm{~mL} / \mathrm{min}$, in down flow manner with the help of a fine metering valve. All the experiments were carried out at room temperature. The effluent solution was collected at different time intervals and the concentration of the fluoride in the effluent solution was monitored by ion selective electrode ${ }^{15}$ using Orion Ion 4 Star Series Meter (Thermo Electron Corporation, USA).

The breakthrough adsorption capacity of fluoride was obtained in column at different cycles using the equation.

$$
q_{e}=\left(\frac{C_{i}-C_{e}}{m}\right) b v
$$

Where $C_{i}$ and $C_{e}$ denote the initial and equilibrium (at breakthrough) fluoride ion concentration $(\mathrm{mg} / \mathrm{L})$ respectively. $b v$ was the breakthrough volume of the NaF solution in liters, and $m$ was the mass of the adsorbent used (g).

After the column was exhausted, the column was drained off the remaining aqueous solution by pumping air. Desorption of solute from loaded adsorbent PCA was carried out by solvent elution method using 0.05 M EDTA as eluent. The EDTA solution was pumped into the column maintained at constant temperature at a fixed flow rate $(0.5 \mathrm{~mL} / \mathrm{min})$. From the start of the experiment effluent samples at different intervals were collected at the bottom of the column for analysis. After the regeneration, the adsorbent column was washed with distilled water to remove EDTA from the column before the influent fluoride solution was reintroduced for the subsequent adsorption-desorption cycles. Adsorption-desorption cycles were performed thrice using the same bed to check the sustainability of the bed for repeated use. The percentage desorption of fluoride was obtained in column at different cycles using the equation.

$$
\% \text { Desorption }=\frac{C_{e}}{C_{i}} \times 100
$$

\section{Results and Discussion}

\section{Characterization}

The FTIR spectra PCA beads before fluoride adsorption (Figure 1(a)) shows absorption bands at $540 \mathrm{~cm}^{-1}$ and $619 \mathrm{~cm}^{-1}$ indicate the presence of $\mathrm{C}-\mathrm{Cl}$ stretching respectively. The bands observed at $1650-1500 \mathrm{~cm}^{-1}$ are for $\mathrm{C}-\mathrm{O}$ stretching or may also be aromatic ether stretching (C-C). The FTIR spectral analysis of PCA after fluoride adsorption (Figure 1(b)) indicates shifts in the peaks at $1610 \mathrm{~cm}^{-1}$ indicating N-H deformation. Further, O-H deformation peaks are observed at $1091 \mathrm{~cm}^{-1}$. The characteristic C-F band was observed at $1033 \mathrm{~cm}^{-1}$. It is evident from the surface, SEM micrographs that PCA beads before fluoride adsorption shows some cracks on the outer surface (Figure 2(a)), but on fluoride loading, the biosorbent surface is somewhat non-uniform and the biosorbent became more brittle shown in Figure 2(b). The surface morphology and texture of fluoride loaded sorbent were completely different from fluoride unloaded sorbent. Figure 2(b) describes the surface characteristics and morphology of the adsorbent after their exposure to fluoride solution. It can be observed that there is change in the morphology of the adsorbents after fluoride sorption. Surface morphological studies revealed that the process of fluoride sorption on PCA beads was predominantly surface phenomenon. 


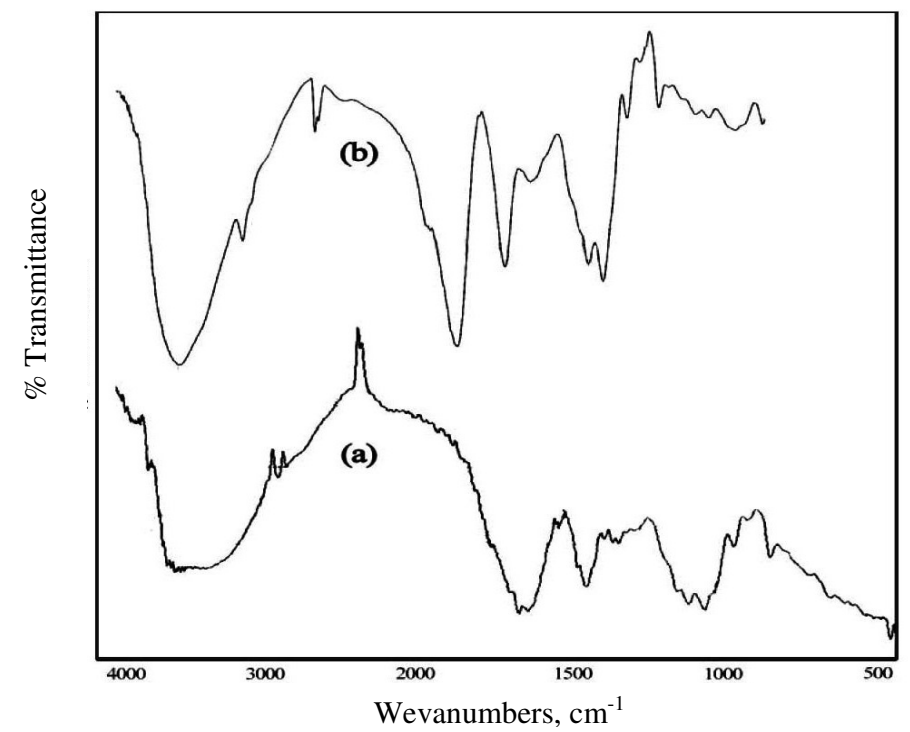

Figure 1. FTIR spectra of (a) PCA and (b) PCA loaded with fluoride.
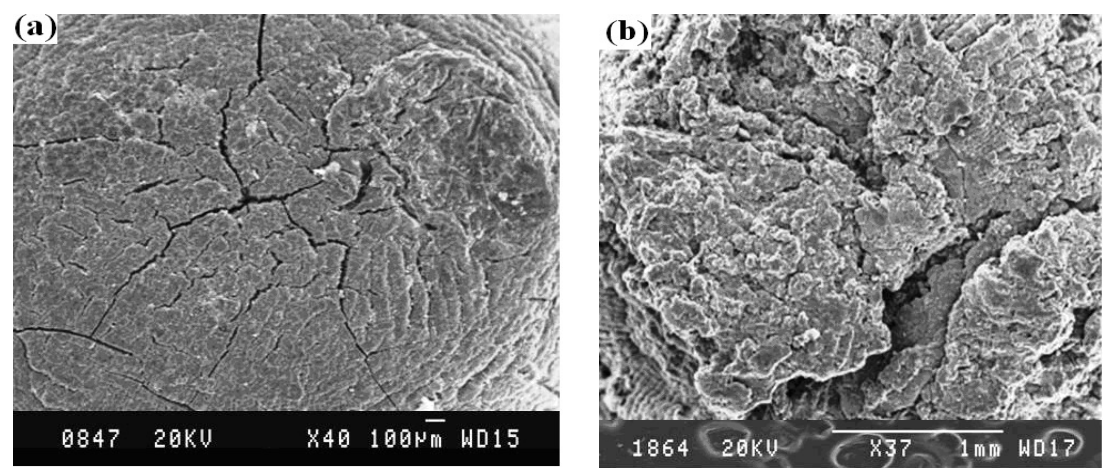

Figure 2. SEM images of (a) PCA and (b) PCA loaded with fluoride.

\section{Column adsorption studies}

Fluoride adsorption dynamics in a fixed bed flow through a sorption column is eventually conducted for multiple reuse of the adsorbent. Column adsorption studies of fluoride on PCA beads at room temperature are investigated using aqueous solution of $10 \mathrm{mg} / \mathrm{L}$ influent concentrations $\left(C_{i}\right)$, at the optimal $\mathrm{pH}$ value. Experimental breakthrough curves, obtained by plotting a graph between the ratios of effluent concentration to initial concentration versus the volume of the effluent, are shown in Figure 3. Breakthrough is supposed to be attained when the concentration of solute in the effluent is equal to the influent concentration and remains unchanged thereon ${ }^{16}$. Faster and effective adsorption of fluoride occurs during the initial phase. Subsequent fluoride adsorption decreases as a consequence of the progressive saturation of the binding sites. It was observed that the column gets saturated after passing $300 \mathrm{~mL}$ of fluoride solution in the first and second cycles, and $280 \mathrm{~mL}$ in the third cycle. The breakthrough adsorption capacity $\left(Q_{e}\right), 1.09,0.94,0.74 \mathrm{mg} / \mathrm{g}$ have been estimated for cycles 1,2 and 3 respectively. The maximum breakthrough adsorption capacity of the adsorbent was observed in first cycle and subsequently decreases in second and third cycles as shown in Table 1. 


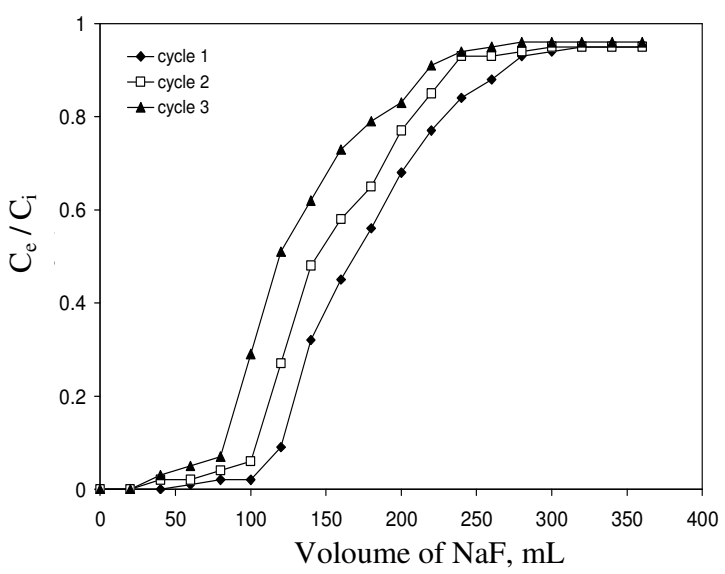

Figure 3. Column breakthrough curves for adsorption of fluoride on PCA.

Table 1. Adsorption capacities of column breakthrough curves for fluoride adsorption.

\begin{tabular}{ccccc}
\hline Cycles & \multicolumn{4}{c}{ Perchloric acid cross-linked calcium alginate } \\
\cline { 2 - 5 } & $\begin{array}{c}\text { Initial } \\
\text { concentration, } \\
\mathrm{mg} / \mathrm{L}\end{array}$ & $\begin{array}{c}\text { Equilibrium } \\
\text { concentration, } \mathrm{C}_{\mathrm{e}}, \\
\mathrm{mg} / \mathrm{L} \text { at breakthrough }\end{array}$ & $\begin{array}{c}\text { Breakthrough } \\
\text { volume of } \mathrm{NaF} \\
(\mathrm{L})\end{array}$ & $\begin{array}{c}\text { Adsorption } \\
\text { capacity, } \mathrm{Q}_{\mathrm{e}}, \\
\mathrm{mg} / \mathrm{g}\end{array}$ \\
\hline $1^{\text {st }}$ cycle & 10 & 0.9 & 0.12 & 1.09 \\
$2^{\text {nd }}$ cycle & 10 & 0.6 & 0.10 & 0.94 \\
$3^{\text {rd }}$ cycle & 10 & 0.7 & 0.08 & 0.74 \\
\hline
\end{tabular}

Table 2. Percentage desorption data of fluoride adsorbed on PCA.

\begin{tabular}{cccccccc}
\hline \multirow{2}{*}{$\begin{array}{c}\text { Time, } \\
\text { min }\end{array}$} & $\begin{array}{c}\text { Volume of } \\
\text { EDTA, } \mathrm{mL}\end{array}$ & $\begin{array}{c}\mathrm{C}_{\mathrm{e}} \text { Cycle } 1 \\
\mathrm{mg} / \mathrm{L}\end{array}$ & $\begin{array}{c}\text { \% of } \\
\text { desorption }\end{array}$ & $\begin{array}{c}\mathrm{C}_{\mathrm{e}}, \\
\mathrm{mg} / \mathrm{L}\end{array}$ & $\begin{array}{c}\text { \% of } \\
\text { desorption }\end{array}$ & $\begin{array}{c}\mathrm{C}_{\mathrm{e}}, \\
\mathrm{mg} / \mathrm{L}\end{array}$ & $\begin{array}{c}\text { \% of } \\
\text { desorption }\end{array}$ \\
\hline 0 & 0 & 0 & 0 & 0 & 0 & 0 & 0 \\
20 & 10 & 4.2 & 42 & 3.1 & 31 & 2.7 & 27 \\
40 & 20 & 5.9 & 59 & 4.8 & 48 & 4.3 & 43 \\
60 & 30 & 8.5 & 85 & 7.6 & 76 & 7.3 & 73 \\
80 & 40 & 6.6 & 66 & 5.5 & 55 & 4.2 & 42 \\
100 & 50 & 4.7 & 47 & 3.4 & 34 & 2.9 & 29 \\
120 & 60 & 3.1 & 31 & 2.5 & 25 & 1.9 & 19 \\
140 & 70 & 1.9 & 19 & 1.7 & 17 & 1.2 & 12 \\
160 & 80 & 1.5 & 15 & 1.3 & 13 & 1.1 & 11 \\
180 & 90 & 1.5 & 15 & 1.3 & 13 & 1.1 & 11 \\
200 & 100 & 1.5 & 15 & 1.3 & 13 & 1.1 & 11 \\
\hline
\end{tabular}

Desorption (regeneration) studies

The regeneration could be accomplished by a variety of techniques such as thermal decomposition, steam washing, solvent extraction, etc. Each method has inherent advantages and limitations. 0.05 M EDTA solution is found to be effective in desorbing and recovering fluoride ions quantitatively from the adsorption bed. EDTA is used as a solvent of choice because its solubility parameters and salvation forces of EDTA overweigh the attractive forces of PCA for fluoride ion. More specifically, maximum desorption is 85,76 and $73 \%$ for first, second and third cycles occurs at $30 \mathrm{~mL}$ and complete regeneration is 15,13 and11\% occurs at about 80 $\mathrm{mL}$ of $0.05 \mathrm{M}$ EDTA solution from the curves, are presented in Table 2. From the Figure 4, it is 
observed that there is an early saturation of the bed with fluoride ion in $2^{\text {nd }}$ and $3^{\text {rd }}$ cycles. The regenerated column is further used for the removal of fluoride. The results indicate that the column gets saturated early and the adsorption capacity decreases slightly. As a result the percent desorption also decreases from first cycle to second cycle.

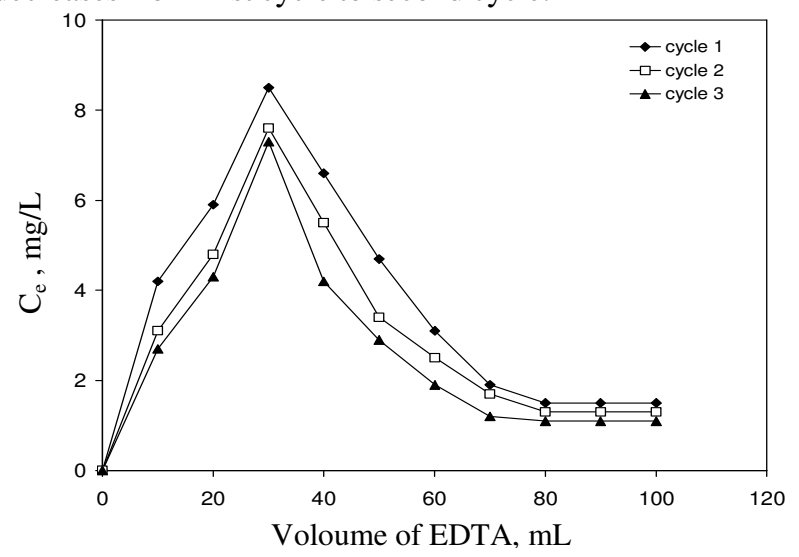

\section{Conclusions}

Figure 4. Desorption curves of fluoride adsorbed on PCA.

Through the present study, it is demonstrates that a PCA was developed by cross-linking perchloric acid on to calcium alginate sorbent could be used successfully for the removal of fluoride from water. The sorbent was characterized on the basis of FTIR, and SEM techniques. The maximum breakthrough adsorption capacity and percent desorption of PCA used in this study was $1.09 \mathrm{mg} / \mathrm{g}$ and $85 \%$ respectively. The results of the present study indicate that the sorbent developed is capable of defluoridation of water.

\section{References}

1. Gupta S K and Desh Pande R D, Depleting groundwater levels and increasing fluoride concentration in villages of Mehsana, Project Report, Gujarat, India, 1998.

2. Underwood E J, Trace Elements in Human and Animal Nutrition, Academic Press, New York, 1997, 545.

3. Fluorine and fluorides. Geneva, World Health Organization, (Environmental. Health Criteria 36), 1984.

4. Susheela A K, Treatise on Fluorosis, Fluorosis research and rural development foundation, India, 2001.

5. Chauhan V S, Dwivedi P K and Iyengar L, J Hazard Mater., 2007, B139, 103-107.

6. Oguz E, J Hazard Mater., 2005, 117, 227-233.

7. Meenakshi S, Sairam Sundaram C and Sukumar R, J Hazard Mater., 2008, 153,164-172.

8. Yadav A K, Kaushik C P, Haritash A K, Kansal A and Rani N, J Hazard Mater., 2006, 128, 289-293.

9. Zhao Y, Li X, Liu L and Chen F, Carbohydr Polym., 2008, 72, 144-150.

10. Mahramanlioglu M, Kizilcikli I and Bicer I O, J Fluorine Chem., 2002, 115, 41-47.

11. Daifullah A A M, Yakout S M and Elreefy S A, J Hazard Mater., 2007, 147, 633-643.

12. Mayadevi S, Indian Chem Eng., 1996, 38, 55-157.

13. Cengeloglu Y, Kir E and Ersoz M, Sep Purif Technol., 2002, 28, 81-86.

14. Islam M and Patel R K, J Hazard Mater., 2007, 143, 303-310.

15. Instruction Manual, Orion Research Inc., Cambridge, MA, 1983.

16. Vijayaraghavan K, Jegan J, Palanivelu K and Velan M, Chemosphere, 2005, 60, 419-426. 


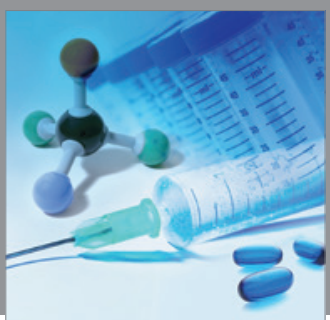

International Journal of

Medicinal Chemistry

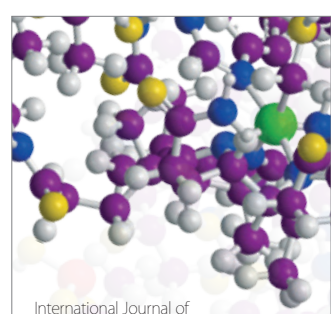

Carbohydrate Chemistry

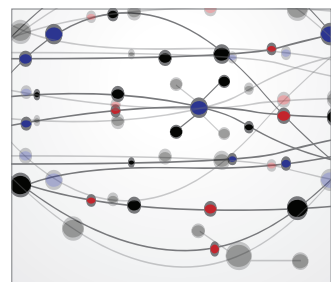

The Scientific World Journal
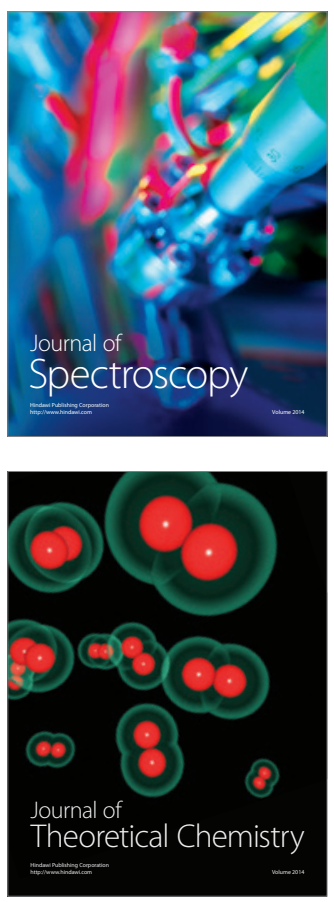
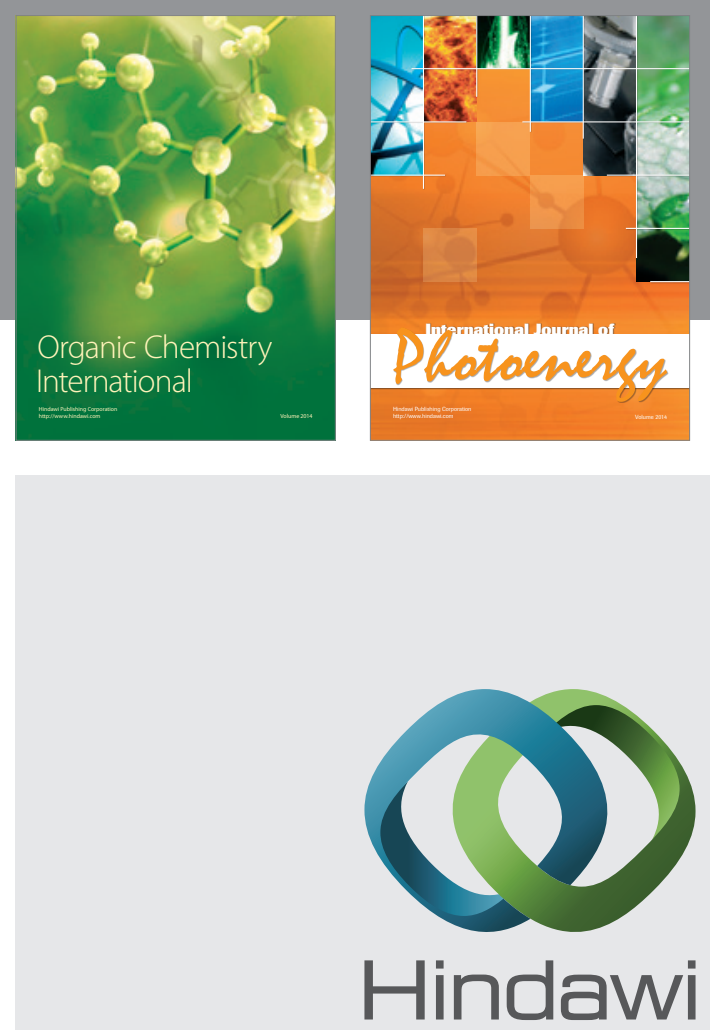

Submit your manuscripts at

http://www.hindawi.com
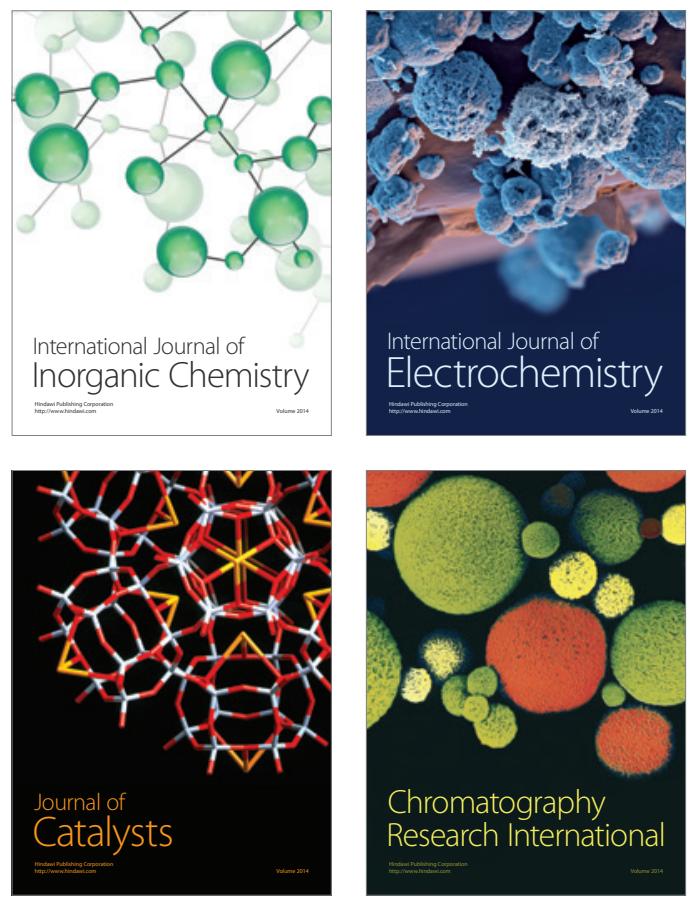
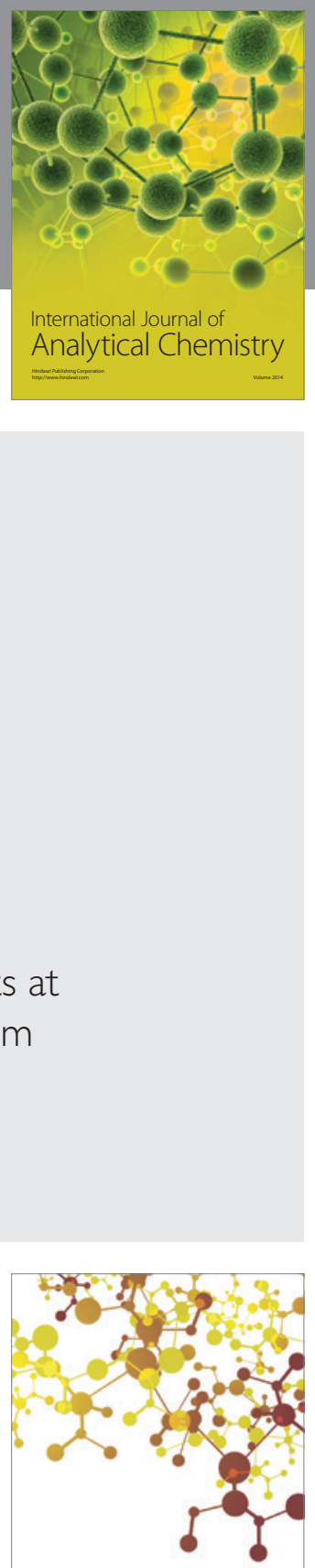

Journal of

Applied Chemistry
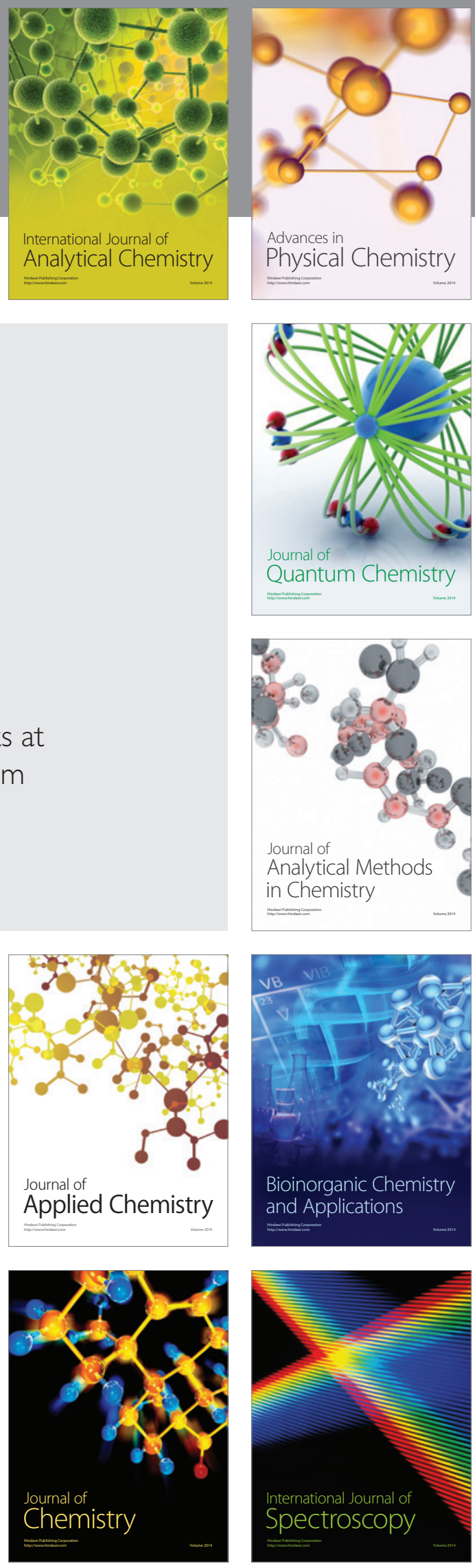